\title{
Sources of negotiation power: An exploratory study
}

\author{
G. Dobrijevic, M. Stanisic and B. Masic \\ Department of Business, Singidunum University, \\ Danijelova 32, 11000 Belgrade, Serbia \\ gdobrijevic@singidunum.ac rs
}

Received April 2010

\begin{abstract}
Power is a very important element of negotiation, because it gives advantage to one party over the other. Various tactics used by negotiators are either aimed at increasing their own power or decreasing the power of the opponent. This paper presents a conceptual analysis and research proposals that build on past research on power and negotiation. The main purpose of the present study was to investigate sources of negotiation power most used among business professionals. We have developed an extensive list of sixteen sources of negotiating power. In this exploratory study we used a qualitative approach based on semi-structured interviews. We chose purposive sampling in order to capture perceptions from different groups of negotiators. The results from thirty-one interviews show that need is the most relied upon source of power in any given situation, followed by perception, credibility, alternative, relationship, intangible factors, authority, material resources, and knowledge/information. Although qualitative research cannot be used to make generalisations about the entire population, this study should help negotiators to focus on the most probable sources of negotiation power and to prepare for negotiations adequately.
\end{abstract}

*To whom all correspondence should be addressed.

\section{Introduction}

This study examines the use of sources of power in negotiation among business professionals. Past research has suggested there are several major sources of power, among them alternatives, information, relationships, material resources and intangible factors. This study is an attempt to make a synthesis of the power sources discussed by different authors.

This study seeks to contribute to the literature on negotiation in several ways. First, we combine theoretical constructs from the literature on negotiation and power in general. We made an extensive list of sources of power, based on theoretical and empirical work of eminent authors. Second, we try to understand sources of power used in actual business negotiations. Understanding the power sources is theoretically and empirically important because it can improve negotiation outcome. Knowing the most used sources of power means knowing the tactics that will be used in negotiations.

Serbia was not included in Hofstede's famous research on cultural dimensions (Hofstede, 1983). For those who work in international business, it is sometimes amazing how different people in other cultures behave. We tend to instinctively assume that, deep inside, all people are the same - but they are not. We cannot make decisions based on how we negotiate in our own home country. This study should help both negotiators from Serbia and abroad to focus on the most probable sources of negotiation power. Lewis (2006: 315) wrote that Serbs value loquacity, generosity, impulsiveness, openness, hospitality etc.; that "in negotiations they are quick at what they see as weakness in others ... Firmness and strict adherence to facts and figures is the only advisable approach for dealing with them." However, he did not make an attempt at deeper analysis of the power sources they use. Therefore, this paper also contributes to the literature on international management in general.

\section{Theoretical background and hypotheses}

"Power is in the eye of the beholder "

Sun Tzu

The study of power and its effect is important in the understanding of negotiation process and relationships flowing from it. Every interaction and every social relationship, inside and outside organisations, involves an exercise of power. In the context of negotiations, we don't analyse the absolute power, but the power which is relevant for a specific conflict or situation.

Power is a very important element of negotiation, because it gives advantage to one party over the other. At the bargaining table power is rarely distributed evenly. In literature there are various definitions of negotiating power. According to Lewicki, Saunders and Barry (2010: 197) it is "the capabilities negotiators can assemble to give themselves an advantage or increase the probability of achieving their objectives". For Salacuse (2003: 206), power is the key element in making, managing and mending deals, and "negotiating power means the ability to influence or 
move the decisions of the other side at the bargaining table in a desired way". Herb Cohen (2006: 235) describes power as "the capability - exercised or not - to produce the intended effect...it's the know-how to influence the behaviour of another." The definition of Maire Dugan (2003) perhaps encompasses the main point of all of them saying that "power is the capacity to bring about change".

There is a difference between real or objective power and perceived or subjective power. We agree with Sun Tzu's famous saying that power is in the eye of a beholder. In order to be efficient, power does not have to be completely in the possession of a negotiator. Instead, the negotiator has to look as if he/she has the power, and that it can be used at will. If you - and other people - believe you have power, than you really have it. Sometimes, making an illusion of power, the negotiator deceives not only his/her opponent, but himself as well. Cultural differences between negotiating parties can influence perception of power and success in use of particular power tactics.

We have to separate the concepts of power and influence (Lewicki et al., 2010). While power is the potential to alter others' attitudes and behaviours, influence consists of actual messages and tactics an individual undertakes in order to change the attitudes and/or behaviours of others. In other words, power is potential influence, while influence is kinetic power (power in use). Achieving successful influence does not necessarily require having power over the individual(s) you seek to influence.

All negotiators want power, they know what they can do by putting pressure to the other side, convince the others to agree with themselves and to make the other party give them everything they want. When a negotiator thinks he has less power than the other party, he/she believes that the other side already possesses some advantage that can be used and consequently starts looking for more power in order to neutralise the other party's power. In another case a negotiator believes that he/she needs to have more power than the opposite party in order to acquire or sustain his/her advantage over the opponent and to get the desired outcome of the forthcoming negotiations. Various tactics used by negotiators are either aimed at increasing their own power or decreasing the power of the opponent. Their result is either equality of power (when both sides have relatively equal level of power) or difference in levels of power (when one side has more power than the other).

The balance of power can vary from one negotiation to another, even if the same people are present on both occasions. In any case, the person who stands to gain the most or lose the least from the process holds the most power (Nierenberg \& Ross, 2003). Empirical evidence shows that power should be discussed in relative rather than absolute terms (Somech \& Drach-Zahavy, 2002).

\section{Sources of negotiation power}

French and Raven (1960) were the first to identify five sources of power: expert power, reward power, coercive power, legitimate, and referent power. A decade later, Sharp (1973) provided a similar list of sources of power (authority, human resources, skills and knowledge, intangible factors, material resources, and sanctions and reprisals). Sources of power in general can be applied to the context of negotiation. Professor of Law emeritus at Harvard Law School and director of the Harvard Negotiation Project Roger Fisher (Fisher, 1983) talks about six categories of power: skill and knowledge, good relationship, elegant solution, legitimacy, commitment, and good alternative to negotiating. On the other hand, Lewicki et al. (2010) combine some other factors into a different list of power sources: information, personal sources, position in an organisation, relationships and context (alternatives, culture and constituents). Salacuse (2003) recognizes difference between physical sources of power, such as capital, technology or organization, and intangible factors, such as an original idea, a strong relationship or a reputation for honesty. Although these two wide groups cover just about any possible source of power, Salacuse omitted making a detailed and comprehensive list. Davis (2007) on the other hand specified eight sources of power in negotiations: need, options, time, relationships, investment, credibility, knowledge, and skill. Whilst Davis presented a more comprehensive list of power sources in negotiation than the other authors, he still did not take into account some of the very important ones, like legitimacy, authority or intangible factors. Surprisingly, none of these eminent authors mentioned perception as one of the sources of power. We strongly believe that perception is one of the most important factors in any negotiation. We agree with one of the main assumptions of Bacharach and Lawler's Dependency theory of bargaining power (Bacharach \& Lawler, 1981), that power in negotiation does not exist apart from bargainers' perceptions of it, whilst it also has objective components, such as money, status, and knowledge. From a negotiator's perspective, his leverage is how the other side perceives it. We don't actually need a strong position, as long as the other side thinks you have one. It's all subjective. If our opponent thinks we can affect their satisfaction or dissatisfaction, we wield the power to determine the outcome (Cohen, 2006). Negotiating power is sometimes based on illusion of the participant that the other side has the power and can use it. In this context Gosselin (2007) has a new and interesting approach to this matter. He sees negotiation power as a function of alternatives:

\section{- $\quad$ Alternative sources for satisfying our own needs}

- $\quad$ Alternative currencies - they have value in proportion to how well they satisfy the needs of the other party (tangible, e.g. money, equipment; and intangible, e.g. recognition, flexibility)

- Alternative skills and behaviours - it is not only having the currency that is important, but also positioning it so that the other side will appreciate and value it.

It has to be admitted, that, although there has been a lot of research of this topic, there has been little attempt to make more extensive research with larger samples. Further studies must be undertaken, better measures must be developed, and larger samples must be used to improve our understanding of the sources of negotiation power. Our research has shown that there are more sources of negotiation power than 
normally found in literature, and that perception is one of the most important.

\section{The purpose of this study}

The main purpose of the study was to investigate sources of negotiation power most used among business professionals. Our research objectives were to: (1) explore all sources of power in negotiation, (2) investigate their use among business professionals, (3) identify the most used, and (4) examine sources of power that are neglected in negotiations. In order to pursue our research objectives, we reviewed the relevant literature on sources of power in general and power in the context of negotiations. This led us to investigate the following research question: Which sources of power are most used in negotiations?

\section{Hypotheses}

Based on our literature review, and in order to answer the study's primary research question, we investigated six specific hypotheses (five of them corresponding with the five contexts of negotiations):

H1: When negotiating with external partners, in case of being the more powerful party, negotiators will use needs, time, and alternatives.

$\mathrm{H} 2$ : When negotiating with external partners, in case of being the weaker party, negotiators will use credibility, alternatives, and perception.

H3: When negotiating with peers, negotiators will use needs, relationships, and coalitions.

H4: When negotiating with subordinates, negotiators will use mostly authority, material resources, and intangible factors.

H5: When negotiating with superiors, negotiators will use needs, information, and credibility.

H6: Source of power rarely used by negotiators is investment.

\section{Research design}

Understanding negotiation depends on the methods used to accumulate the knowledge about it, (e.g. observation and theory building). Methodological problems unique to negotiation research are complexity of the phenomenon, multi-disciplinary nature, lack of time resulting from the crisis-nature of negotiation and the present lack of methods to measure relationships between variables. Major impediments to progress must be the inability to formulate the most pertinent questions and to construct the most useful integration of information. It is well known that observation can alter the negotiation outcome, so we chose a qualitative approach based on semi-structured interviews. There were six broader themes in the interviews:
1. Negotiation with outsiders when we have more power than the other side

2. Negotiation with outsiders when we have less power than the other side

3. Internal negotiations: Negotiation with peers

4. Internal negotiations: Negotiation with subordinates

5. Internal negotiations: Negotiation with superiors

6. Sources of power we never use

For the purpose of this paper, we have developed an extensive list of sixteen sources of negotiating power, based on the works of Fisher (1983), Davis (2007), Fairholm (2009), Lewicki et al. (2010), Sharp (1973), and Gosselin (2007).

1. Need. The essential question here is: who needs the negotiation more, one side or the other. The more you need to reach a conclusion, the more power the other side will have.

2. Alternatives / Options. What are the options for each party if an agreement is not reached? The better your BATNA - best alternative to a negotiated agreement (Fisher \& Ury, 1981), the more power you have.

3. Time / Deadline. It refers to any impending events that place a deadline on either negotiating party. It can also mean waiting for the right moment or starting negotiations with an initiative.

4. Relationships. If negotiators have high quality relationships with the other side, they have relationship power.

5. Investment. The more effort or resources someone invests, the more committed he or she will be to reaching an agreement, and that will give more power to the other party.

6. Credibility. Material proofs of your former successful work increase your negotiating power, as well as having large and important parties among your partners.

7. Information / Knowledge. Knowledge is power. The more knowledge you have about the other party, the more negotiating power you will have. In international negotiations it implies thorough understanding of the other party's culture.

8. Skills. Among others: the ability to listen to others, empathy, sensitivity to others, clear communication, speaking foreign languages etc. Negotiating skills can be both learned formally and acquired through experience.

9. Elegant solutions. In any negotiation, there are many shared and conflicting interests. One way to influence 
the other side is by finding a good solution to the problem. The more complex the problem, the more influential an elegant answer is.

10. Legitimacy. A negotiator should look for objective standards and criteria, as well as propose solutions that are legitimate in the eyes of the other side.

11. Commitment. There are two different kinds of commitments: affirmative and negative (willingness or unwillingness to reach an agreement).

12. Authority. The perception among the governed that the leader has the right to give them directives. It includes rewards and sanctions towards subordinated.

13. Coalitions. Includes making alliances with the more powerful.

14. Intangible factors, such as psychological and ideological factors, habits and attitudes toward obedience and submission, and the presence or absence of a common faith, ideology, or sense of mission. Includes reference power.

15. Material resources in the form of control over wealth, property, natural resources, communications, and transportation. Include budgeting, routine decisions on responsibilities and tasks, information processing, controlling agenda and schedules.

16. Perception. The more power the other party thinks you have, the more power you actually have.

Since the participants were not familiar with negotiation theory, but were people who negotiate in their daily jobs, they talked about the actual tactics they used in different negotiation contexts. For each context they chose up to three sources of power, and only one source of power they use never or very rarely. We then translated those tactics into codes based on the list of sixteen sources of negotiating power. For example, tactic of building relationships with appropriate third parties was classified as Coalitions, mentioning BATNA at the beginning of negotiations was classified as Alternatives / Options, and dispensing rewards to the subordinated as Authority.

\section{Participants}

We chose a sampling strategy that would capture perceptions from different groups of negotiators. No sampling frame was available. We used purposive sampling, trying to have participants from business and non-profit organisations, private and public sector, from national and international organisations, from Belgrade and the rest of Serbia, both men and women. There were thirty-one participants, eighteen men and thirteen women aged 30 to 64. The participants were people who negotiate mainly with external partners, but also with parties from the same organisation. The majority of the interviewees have some experience in negotiating in international context. Ten of the thirty-one participants work in multinational organisations.
Three participants finished high school, twenty-five participants have Bachelor degree, there is one Master of Science and two hold $\mathrm{PhD}$ in economics. The research was conducted during February and March 2010. Twenty-four participants live in Belgrade, and seven in other regions of Serbia. Eight of the interviews were conducted by telephone.

\section{Limitations}

Negotiation research methodology, as in the case of other human behavioural research, relies heavily on assumptions to provide the frame for theory development, which in turn forms the basis for the selection and development of research methods and ultimately determines the resulting data.

Another limitation is a result of the scope and geographical spread of our research. Qualitative research employing semi-structural interviews cannot be used to make generalizations about the entire population, since it is based on a small and unrepresentative number of cases. However, it does help us understand power and its use in negotiations, since circumstances in each negotiation are complex and dynamic, and depend on multiple factors.

\section{Results}

Qualitative data collected using semi-structured interviews were subsequently analyzed using quantitative procedures. Table 1 presents all the results from the interviews.

The highest scores for each of the subjects are:

1. In negotiation with outsiders when we have more power than the other side - need (25), alternatives (25), and perception (17) are most used sources of power.

2. In negotiation with outsiders when we have less power than the other side - credibility (22), need (20), and perception (15) are most used.

3. When negotiating with peers - relationships (24), need (21), and intangible factors (13) are the most important.

4. When negotiating with subordinates, authority (26), material resources (17), and need (17) are most used.

5. When negotiating with superiors - need (22), knowledge/information (19), and credibility (17) are the most important.

6. Sources of power we never use. - More than half of the participants (19) said they never use investment as a source of power and almost one third (10) mentioned commitment. 
Table 1: Sources of power in different negotiation contexts

\begin{tabular}{|c|c|c|c|c|c|c|c|c|c|c|c|c|c|c|c|c|}
\hline 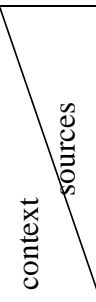 & $\begin{array}{l}\ddot{J} \\
\ddot{Z}\end{array}$ & 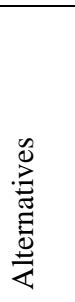 & $\stackrel{\mathscr{g}}{g}$ & 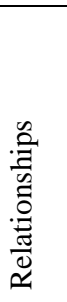 & 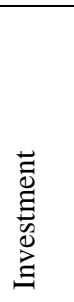 & 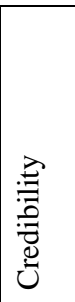 & 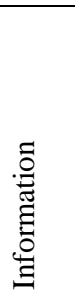 & $\frac{a}{\bar{n}}$ & 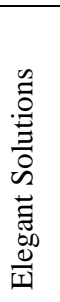 & 菍 & 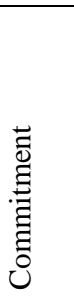 & $\begin{array}{l}\stackrel{\overrightarrow{0}}{0} \\
\text { 吾 } \\
\text { 要 }\end{array}$ & 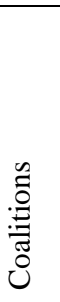 & 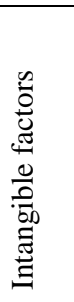 & 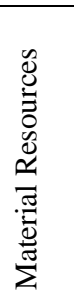 & 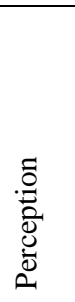 \\
\hline 1 & 25 & 25 & 12 & & & & 8 & & & & & & & & & 17 \\
\hline 2 & 20 & 4 & & 5 & & 22 & 9 & 11 & 2 & 1 & & & 3 & 1 & & 15 \\
\hline 3 & 21 & & & 24 & & 4 & 10 & 5 & 2 & & 2 & & & 13 & 3 & 9 \\
\hline 4 & 17 & 7 & & & & & 7 & 3 & & 4 & & 26 & & 6 & 17 & 6 \\
\hline 5 & 22 & & & 3 & & 17 & 19 & 15 & 6 & 4 & & & & & & 7 \\
\hline 6 & & & 1 & & 19 & & & & 1 & & 10 & & & & & \\
\hline
\end{tabular}

1. Negotiation with outsiders when we have more power than the other side

2. Negotiation with outsiders when we have less power than the other side

3. Internal negotiations: Negotiation with peers

4. Internal negotiations: Negotiation with subordinates

5. Internal negotiations: Negotiation with superiors

6. Sources of power we never use

In case of being the more powerful party when negotiating with external partners, findings indicate that the majority of negotiators would use need and alternatives, and more than half would use perception, which partly supports H1. Somewhat unexpectedly, only twelve would use time as source of power in the same situation. We expected higher score for time, because the more powerful negotiator could use time practically not spending any of the more "tangible" sources of power. If they are the less powerful party, credibility, need, and perception are most used. Again results partly support $\mathrm{H} 2$ - instead of alternatives there is need as a widely used source of power. On the other hand, H3 is fully proved: when negotiating with peers, negotiators use relationships, need, and intangible factors, as proposed. Results partly support H4: authority and material resources are mostly used when negotiating with subordinates, but instead of proposed intangible factors, more than two-thirds chose need as the third most used source of power. When negotiating with superiors, need, credibility, and knowledge/information will be used, and this fully supports H5.

Regarding H6, the data indicate that investment will be least used as a source of power, which supports the hypothesis.

\section{Discussion}

The first goal of the present research study was to explore all sources of power in negotiation. We reviewed extensive relevant literature, and identified sixteen sources of power used in different negotiation settings: need, alternatives/options, time/deadline, relationships, investment, credibility, information/knowledge, skills, elegant solutions, legitimacy, commitment, authority, coalitions, intangible factors, material resources, and perception. Then through semi-structured interviews we investigated their use among business professionals. After quantifying our qualified data, we were able to identify the most used sources of power in different negotiation settings.
Need appears as the most widely used source of power, regardless of the negotiation setting. When we look at overall results, need is among the three most used sources of power in any given situation. After that, perception and credibility appear twice, and then the most used sources of power (with no particular order): alternative, relationship, intangible factors, authority, material resources and knowledge/information. Our final goal was to investigate which sources of power are least used in negotiations, and the results suggest investment and commitment.

We were surprised to find that alternatives/options and knowledge/information appear among the top sources only in one case each (alternatives when negotiating with external partners when we hold more power; and knowledge/information when negotiating with superiors).

Although there has been some very important research in the area of negotiation during the last decades, a great deal of work still remains to be done towards formulating the best general advice to negotiators to increase their ability to influence others, as Fisher proposed in his article (Fisher, 1983). Some of that work relates to what can be done to acquire power in advance of a negotiation, and some relates to how best to use the power one has. We do not attempt to advance propositions that will be true in every case, only to suggest some rules of thumb that should be helpful in negotiation in Serbia, considering that negotiation behaviours vary across cultures.

\section{Recommendations for future research}

The results of this study offer interesting opportunities for future research. While this particular study utilized a group of thirty-one professionals limited to Serbia, it could be replicated on a sample that would represent a wider region. Further research could probably explore a more diverse array of social groups and settings. Another research stream might explore the factors determining male and female uses 
of power in negotiations, since the results of one previous study of negotiation in Serbia (Dobrijevic, 2009) differ from another study (Branham et al., 2005) undertaken in the USA. Branham's study indicates that, when compared with their male counterparts, women are more likely to utilize a collaborative conflict resolution style and men are more likely to avoid conflict. As collaboration is generally considered more productive and avoidance more disruptive in the conflict resolution process, the study suggests that women may possess more effective conflict resolution attributes than their male counterparts. The research in Serbia shows that women equally concentrate on conflict avoidance and collaboration with the other party.

It would also be interesting to engage in a multiple case comparison of Serbian business negotiators with other cultures, according to Hofstede's cultural dimensions (Hofstede, 1983) and Inglehart's cultural clusters (Inglehart, 2000). The results could be used in negotiation planning with domestic and foreign partners, in order to enhance the negotiation results. That would be interesting for negotiators from the Balkans, who, despite their recent differences, are bound to come into closer contact. It would also be of interest to negotiators who come from different cultures, since Serbia as other countries from the region, is getting more open to foreign investment.

\section{References}

Bacharach, S.B. \& Lawler, E.J. 1981. Bargaining: Power, tactics, and outcomes. San Francisco: Jossey-Bass, Inc.

Brahnam, S.D. et al. 2005. 'A gender-based categorization for conflict resolution', Journal of Management Development, 24(3): 197-208.

Cohen, H. 2006. Negotiate this! By caring, but not that much. New York, NY: Warner Business Books.

Davis, K. 2007. 'Eight sources of power in a sales negotiation'. [online]

http://www.businessknowhow.com/marketing/eightsourceso fpower htm.

Dobrijevic, G. 2009. 'Business negotiation strategy in contemporary organizations'. Unpublished $\mathrm{PhD}$ thesis, Singidunum University, Belgrade.

Dugan, M. A. 2003. 'Power'. [online]

URL:http://www.beyondintractability.org/essay/Power.
Fairholm, G. 2009. Organizational power politics: Tactics in organizational leadership. $2^{\text {nd }}$ Edition. Santa Barbara, CA: Greenwood Publishing Group.

Fisher, R. 1983. 'Negotiating power: Getting and using influence', American Behavioral Scientist, 27(2): 149-166.

Fisher, R. \& Ury, W. 1981. Getting to yes: Negotiating agreement without giving in. Boston, MA: Houghton Mifflin.

French, J. P. R. Jr. \& Raven, B. 1960. 'The bases of social power'. In Cartwright, D. \& Zander, A. (Eds.). Group dynamics. New York: Harper and Row.

Gosselin, T. 2007. Practical negotiating: Tools, tactics and techniques. Hoboken, New Jersey: John Wiley \& Sons, Inc.

Hofstede, G. 1983. 'National cultures in four dimensions', International Studies of Management and Organization, 13(2): 46-75.

Inglehart, R. 2000. 'Culture and democracy'. In Harrison, L. E. \& Huntington, S. P. (Eds.). Culture matters: How values shape human progress. New York, NY: Basic Books.

Lewicki, R., Saunders, D. M. \& B. Barry, B. 2010. Negotiation. $6^{\text {th }}$ Edition. Singapore: McGraw-Hill/Irwin.

Lewis, R. D. 2006. When cultures collide: Leading across cultures. $3^{\text {rd }}$ Edition. Boston, MA: Nicholas Brealey International.

Nierenberg, J. \& Ross, I. 2003. The secrets of successful negotiation: Effective strategies to improve your negotiating skills. London: Duncan Baird Publishers.

Salacuse, J.W. 2003. The global negotiator: Making, managing and mending deals around the world in the twenty-first century. New York, NY: Palgrave MacMillan.

Sharp, J. 1973. Power and struggle: Politics and nonviolent actions, Part I. Boston. MA: Porter Sargent.

Somech, A. \& Drach-Zahavy, A. 2002. 'Relative power and influence strategy: The effects of agent/target organizational power on superiors' choices of influence strategies', Journal of Organizational Behavior, 23(2): 167-179. 


\section{Appendix: Interview themes}

In business environment, there are six possible situations:

1. Negotiation with outsiders when we have more power than the other side

2. Negotiation with outsiders when we have less power than the other side

3. Internal negotiations: Negotiation with peers

4. Internal negotiations: Negotiation with subordinates

5. Internal negotiations: Negotiation with superiors

6. Sources of power we never use

There are various sources of power used in negotiations. Please mark those you use most:

1. Need. Who needs the negotiation more, you or the other side? The more you need to reach a conclusion, the more power the other side will have.

2. Alternatives / Options. What are the options for each party if an agreement is not reached? The better your alternative to a negotiated agreement, the more power you have. Example: mentioning alternatives.

3. Time / Deadline. It refers to any impending events that place a deadline on either negotiating party. It can also mean waiting for the right moment or starting negotiations with an initiative. The more time you have for negotiations, the more power you have.

4. Relationships. If you have high quality relationships with the other side, you have relationship power.

5. Investment. The more effort or resources you invest, the more committed you will be to reaching an agreement, and that will give more power to the other party.

6. Credibility. Material proofs of your former successful work increase your negotiating power, as well as having large and important parties among your partners.

7. Information / Knowledge. Knowledge is power. The more knowledge you have about the other party, the more negotiating power you will have.

8. Skills. Among others: the ability to listen to others, empathy, sensitivity to others, clear communication, speaking foreign languages etc. Negotiating skills can be both learned formally and acquired through experience.

9. Elegant solutions. In any negotiation, there are many shared and conflicting interests. One way to influence the other side is by finding a good solution to the problem. The more complex the problem, the more influential an elegant answer is.

10. Legitimacy. You should look for objective standards and criteria, as well as propose solutions that are legitimate in the eyes of the other side. Example: have researched precedents or expert opinion.

11. Commitment. There are two different kinds of commitments: affirmative and negative (willingness or unwillingness to reach an agreement). Example: an offer what I am willing to do (under certain conditions) or what I am willing to agree to; a commitment that I am unwilling to make certain agreements.

12. Authority. The perception among the governed that the leader has the right to give them directives. It includes rewards and sanctions towards subordinated.

13. Coalitions. Includes making alliances with the more powerful. Example: building relationships with appropriate third parties

14. Intangible factors, such as psychological and ideological factors, habits and attitudes toward obedience and submission, and the presence or absence of a common faith, ideology, or sense of mission. Includes reference power.

15. Material resources in the form of control over wealth, property, natural resources, communications, and transportation. Include budgeting, routine decisions on responsibilities and tasks, information processing, controlling agenda and schedules.

16. Perception. The more power the other party thinks you have, the more power you actually have.

Mark 3 sources of power (for situations 1-5). For situation No. 6 please mark any number of sources.

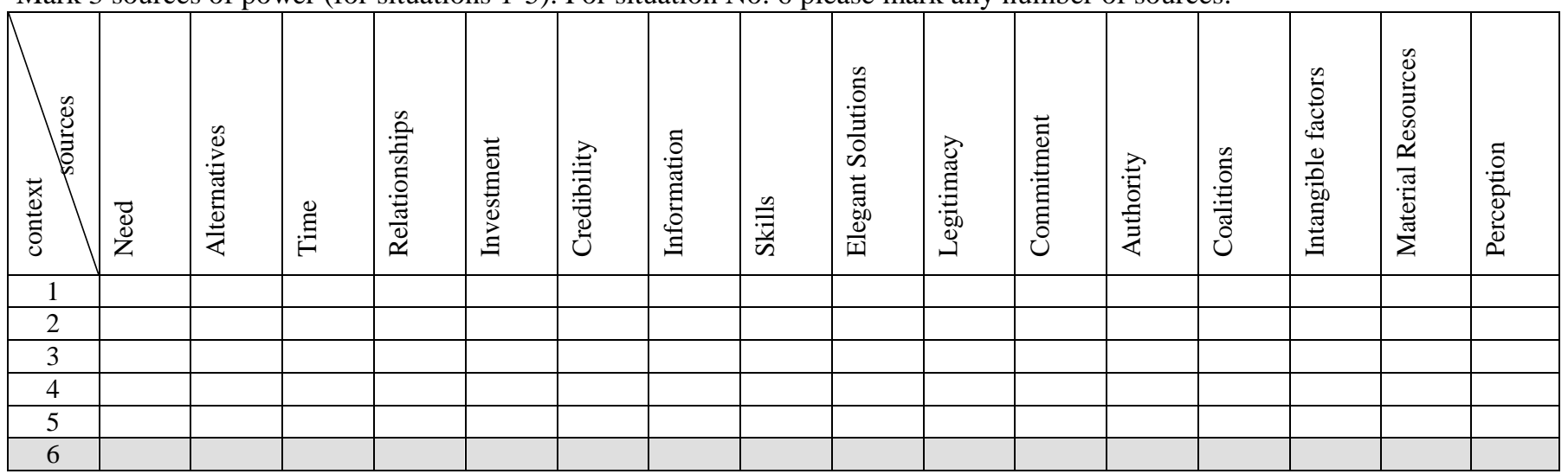


